\title{
A review on borehole instability in active shale formations: interactions, mechanisms and inhibitors
}

\author{
Raoof Gholami ${ }^{1}$, Henry Elochukwu ${ }^{1}$, Nikoo Fakhari ${ }^{2}$, Mohammad Sarmadivaleh ${ }^{3}$ \\ 1-Department of Petroleum Engineering, Curtin University, Malaysia \\ 2-Department of Chemical Engineering, Curtin University, Malaysia \\ 3-Department of Petroleum Engineering, Curtin University, Australia
}

\begin{abstract}
Shale formations are known for their chemical interactions with water based muds which may result in swelling, bit balling or even closure of the wellbore. As a result, eco-friendly water based fluids with inhibitive characteristics are required for drilling through shale formations. The aim of this study is to provide a deeper insight into drilling through shale formations by providing few approaches for different circumstances. Many inhibitors developed so far are introduced with their mechanism of shale inhibition presented. It appears that silicate based muds and thermally activated mud emulsion (TAME) are the best option to mitigate shale related issues, but more studies are required to provide a permanent solution for this very complicated issue, especially under HPHT conditions.
\end{abstract}

Keywords: Active shales, clays, inhibition, water based muds, encapsulation

\section{Introduction}

Shale formations often comprise up to $75 \%$ of the overall intervals drilled in a given well and are the main cause of wellbore instability experienced in more than $90 \%$ of cases (Steiger and Leung, 1992). These instabilities are linked to mechanical and physico-chemical interactions between the drilling muds and shale formations. Mechanical interactions are time independent phenomena and directly linked to the appropriate selection of mud weight (Zeynali, 2012). On the contrary, physico-chemical processes are time dependent (Lal, 1999; Osuji et al., 2008; Zeynali, 2012) and related to the interaction taking place between shales and Water Based Muds (WBMs). They induce swelling and reduces the strength of the wellbore, causing 'stuck pipe', bit balling, sloughing, reduction of the hole cleaning efficiency, and even loss of wells.

There have been a large number of studies carried out to resolve the issue of instability posed by shale swelling. Oil Based Muds (OBMs) were the first option recommended as a 'certain' solution to avoid borehole instability caused by shales. Their applications provided outstanding clay inhibition, lubricity, temperature stability, tolerance to contamination, and corrosion protection (Dye et al., 2006). However, the environmental concerns and regulations on OBMs have resulted in their limited applications.

As a result, many WBMs and non-aqueous fluids together with different types of shale inhibitors have been developed. These inhibitors (stabilizers), which can reduce or eliminate swelling, 
dispersion, and clay-water interactions, are generally categorized into several classes including: inorganic salts, potassium formate, polymers with special shale affinity, asphalts, sugars and sugar derivatives, glycols and silicates (Van Oort, 2003). However, due to anisometric and irregular shape of clay minerals, the broad particle size distribution, different types of charges (permanent charge on the faces and $\mathrm{pH}$ dependent charges at the edges), the heterogeneity of layer charges, the pronounced cation exchange capacity, disarticulation of smectite and flexibility of layers, none of these inhibitors have been totally successful in securing the stability of borehole. For instance, potassium chloride was the earliest and perhaps the most widely used agent. When combined with other additives such as partially hydrolysed polyacrylamide (PHPA) (Steiger, 1981), polyglycol (Brady et al., 1998) and silicates (Guo et al., 2006), effective inhibition was achieved by synergetic effects, but its significant flocculation in the mud may have negative impact on the rheology and filtration control (Chesser, 1987). Moreover, a large quantity of $\mathrm{KCl}$ is often required to achieve a good inhibition efficiency which due the high concentration of chloride remained in the mud after interacting with shales may cause serious environmental issues and contaminations (Guerrero et al., 2006). Cationic polymers are another category of inhibitor and when added to water based muds can be as effective as OBM. However, they are incompatible with other additives commonly used to change the physical and chemical characteristics of WBMs (Patel et al., 2007). As a result, developing a new eco-friendly shale inhibitor or 'novel' water based mud which can be as efficient as an OBM is still in demand.

The aim of this paper is to provide a review on different aspects of wellbore instability caused by different types of shales. Various inhibitors developed so far are introduced with their limitations reported on various circumstances. A general procedure is recommended as a guideline which may be followed to select a suitable WBM for applications under different circumstances.

\section{Shale}

Shales are known sedimentary rocks in marine basins, composed mainly of mud, silts and clays, although burial depth and tectonic stresses may alter their composition in different ways (Moslemizadeh et al., 2015). Clay minerals are generally flaky, mica-type crystalline in nature. These flakes consist mainly of crystal platelets called unit layers which may have multiple octahedral or tetrahedral sheets linked together by oxygen atoms. In the octahedral sheet, six oxygen atoms form an octahedron with a metal atom in the middle. In the tetrahedral sheet though, a silicon atom is located in the centre of four atoms and forms a tetrahedron. The $\mathrm{O}^{2-}$ layers of each tetrahedral sheet are adjacent to $\mathrm{O}^{2-}$ layers of the neighbouring lattice, resulting in creation of a week bond and perfect cleavage plane between platelets. As a result, bound water can be oriented between platelets causing swelling and dispersion.

The difference between clays is primarily related to the substitution of the aluminium in the central octahedral layers and silica in the outer tetrahedral layers by other multivalent cations. This creates a charge imbalance which is compensated by the adsorbed exchange of cations in the interlattice zone (i.e., other multivalent ions). Ions may also be adsorbed on the clay crystal 
edges and exchanged with other ions in the water when the $\mathrm{pH}$ value of the aqueous system varies (Horton and Jones, 2008). Based on salinity, density, Cation Exchange Capacity (CEC) and water content, shale rocks can be divided into five groups (Fang, 1999): soft, firm, hard, brittle and firm-hard as given in Table 1.

Table 1: Shale classifications based on physico-chemical characteristics (Obrien and Chenevert, 1973;

Fang, 1999)

\begin{tabular}{|c|c|c|c|c|c|}
\hline Shale Type & Clay Minerals & $\begin{array}{c}\text { Water Content } \\
(\%)\end{array}$ & $\begin{array}{c}\text { Density } \\
(\mathrm{g} / \mathrm{cc})\end{array}$ & CEC (meq/100g) & Salinity (g/l) \\
\hline Soft & High smectite, some illite & $25-70$ & $1.2-1.5$ & $20-40$ & $>20$ \\
\hline Firm & $\begin{array}{c}\text { High illite, fairly high } \\
\text { smectite }\end{array}$ & $15-25$ & $1.5-2.2$ & $10-20$ & $20-60$ \\
\hline Hard & $\begin{array}{c}\text { High in mixed-layer, illite, } \\
\text { chlorite }\end{array}$ & $5-15$ & $2.2-2.5$ & $3-10$ & $40-100$ \\
\hline Brittle & $\begin{array}{c}\text { Moderate illite, } \\
\text { moderate kaolinite and } \\
\text { chlorite }\end{array}$ & $2-5$ & $2.5-2.7$ & $0-3$ & $60-330$ \\
\hline Firm-Hard & $\begin{array}{c}\text { High illite, moderate } \\
\text { chlorite }\end{array}$ & $2-10$ & $2.3-2.7$ & $5-20$ & $40-250$ \\
\hline
\end{tabular}

\subsection{Clay Types}

Shales may have different kinds of clays with various structures which due to their nature and surface charge may induce wellbore instability and cuttings disintegration issues. In this section, these clays are introduced and their sensitivity to WBMs are discussed.

\subsubsection{Smectite (Montmorillonite, Bentonite)}

Montmorillonite, as the main member of the smectite family and the primary material of bentonites, has a high CEC which may alter the tendency of shales to hydrate based on the type of cations and the $\mathrm{pH}$ of the drilling mud. They are composited of three repeating base units: a silica tetrahedron, an alumina octahedron and a silica tetrahedron. The main feature of the smectite group is their wide gap between units and weak bonding which leads to a significant swelling tendency. One can try to decrease the swelling tendency of these clays by substituting the counterions such as $\mathrm{Na}^{+}$and $\mathrm{Ca}^{++}$on the shales. The potassium ion can also be used to reduce the swelling tendency because of its unique hydrated size and ability to fit exactly into the tetrahedral layer of active clays. If the potassium ion is exchanged into the clay lattice, it is very difficult to remove it and the lattice is essentially fixed. It should be noted that montmorillonite can be found at shallow structures and it becomes more like illite in deep intervals, but the produced illite may still have swelling tendency (Caenn et al., 2011). 


\subsubsection{Illite}

Unlike montmorillonite, Illite has a lesser tendency to hydrate in fresh water, even though it has a same two silica tetrahedral sheets and a central octahedral alumina sheet. In fact, it does not have an expanding lattice and as such no water can penetrate between the layers. The strong interlayer bonding might be related to the higher charge nearer the surface in the tetrahedral sheet. Ion exchange can still take place at the exterior surfaces of each layer in illites but the increase in volume is much less than that caused by the hydration of montmorillonite. Illite is produced by the alteration of muscovite and feldspar in weathering and hydrothermal environments. As a result, the space between individual clay crystals is occupied by poorly hydrated potassium cations which prevents illite to show any tendency for swelling (Patel et al., 2007). However, there is another type of illite produced by the transformation of smectite in deep intervals where high pressure high temperature conditions prevail. These mixed layer illites may have more tendency for swelling than their original versions.

\subsubsection{Chlorite and Kaolinite}

Chlorite and Kaolinite, as the other members of the clay family, do not have a significant hydration ability, although kaolinite can disperse. It is a layered silicate mineral, with one tetrahedral sheet of silica linked to octahedral sheets of alumina octahedral. Kaolinite has a low swelling tendency and poor cation exchange capacity (1-15 meq/100 g). It is a soft and white mineral produced by the chemical weathering of aluminium silicates such as feldspar. Shales with a significant amount of Kaolinite often reveal a brittle behaviour and are the subject of interest in mechanical stability issues of wellbores (Anderson et al., 2010).

The chlorites, on the other hand, are a group of phyllosilicate minerals, described by four members based on their chemistry which are known as Clinochlore, Chamosite, Nimite and Pennantite. The great range in composition results in considerable variation in their physical and chemical properties and allows them to exist over a wide range of temperature and pressure conditions.

\subsection{Clays used in Drilling Muds}

Although the drilling fluid composition has moved away from the historical clay-based muds, bentonite, attalpulgite and hectorite clays are still used in low concentrations as filtration controls and a low shear viscosity builder (Guerrero et al., 2006). The main commercial clay is bentonite, a member of the montmorillonite (smectite) family which is further discussed in the next section.

\subsubsection{Bentonite}

Once bentonite is added to freshwater, it may cause (Mitchell and Miska, 2011):

I. Aggregation: This is the natural state of clay when bentonite occurs as sheets of clay. 
II. Dispersion: When bentonite is added to water, the sheets separate (disperse) in the water.

III. Flocculation: After the clay sheets have depressed, the platelets arrange themselves according to their electrical surface charges: edge (positively charged) to face (negatively charged) or edge to edge. Flocculation is not desirable, since it supports a high yield point, high gel strength and high filtration. Common causes of flocculation are high ionic strength (high concentrations of salts), a high concentration of shale in the mud and high temperature, or contamination with an influx coming from the formations.

IV. Deflocculation: Deflocculants are used to neutralize the charges on the clay surfaces. It should be noted that a deflocculated mud is not the same as a dispersed mud. Traditionally, tannins, lignosulfonates and lignites are used as deflocculants but many high performance WBMs use short-chained polymers or surfactants instead.

It is clear that bentonite cannot be added directly to a mud containing salt. The salt ions 'shield' the clay platelets and bentonite can no longer hydrate, resulting in poor rheological changes in the mud. In fact, bentonite needs to be prehydrated in freshwater before adding salts.

\subsubsection{Other Clays in Drilling Fluids}

Hectorite and attalpulgite may have applications as a viscosity builder under HPHT and saltwater drilling conditions. Unlike the platelet-shaped bentonite, the needle-shaped hectorite and attalpulgite are made up with double silicate chains. They do not swell, have a high affinity to water but do not show any impact on filtration control (Caenn et al., 2011).

Clays can also be used in OBMs as a viscosity builder. However, their surface needs to be coated with "quaternary amine" for providing gel structures. It is sometime observed that drilled clay solids in the drilling fluid are used for filtration control. This practice is dangerous because drilling solids, although mostly clay, are in a very poor state. They may increase plastic viscosity excessively and decrease the quality of filter cake (Mitchell and Miska, 2011).

\subsection{Shale related Instability}

Due to borehole failure, accumulation of cuttings and swelling which often take place in different shale formations, drilling parameters may change significantly. This may result in stuck pipe, difficulty in circulation and bottom hole cleaning efficiency (Beihoffer et al., 1988). There are several mechanisms involved in shale related instabilities including: pore pressure diffusion, plasticity, anisotropy, capillary effects, osmosis, and physicochemical alterations (Fink, 2011). These mechanisms can be explained by: 1) movement of fluid between interlayers of shales, 2) changes within the stress and strain regime during filtration, and 3) softening and erosion caused by mud invasion. 
There are generally four types of shale in which these mechanisms may manifest during drilling, including, hydrable shale, brittle shale, abnormally pressurized shale and tectonically stressed shale.

\subsubsection{Hydrable shales}

Hydration (swelling) and dispersion are related phenomena but their occurrence depends, to a large extent, on the amount and type of clays within the structure of the shale. Swelling takes place because of surface (crystalline) and osmotic hydrations (Patel et al., 2007). Surface hydration is not often considered to be of great significance and causes only a slight expansion induced by the addition of few molecules of water on the surfaces of the clays. In this type of hydration, hydrogen bonding holds water molecules to the oxygen atoms where layers of water molecules form a quasi-crystalline structure between unit layers, which increases the c-spacing. Osmotic hydration, on the other hand, is the primary concern which leads to the significant expansion of clays and closure of the borehole. It is induced when the concentration of cations between unit layers in a clay mineral is higher than the surrounding water. As a result, water is osmotically gone between the unit layers and the c-spacing increases. Osmotic swelling creates a larger volume expansion increase compared to the surface hydration, but only a few clays such as montmorillonite can swell in this manner (Patel et al., 2007). Generally, cations with high valences are more strongly adsorbed than those with low valences. Thus, clays with low valence exchangeable cations have more tendency for swelling than clays whose exchangeable cations have high valences (Anderson et al., 2010).

Unlike swelling, dispersion is a repeated and rapid disintegration of the shale surface, induced because the strength of the bonds between clay particles is reduced when water is adsorbed and pore pressure increases. This is also responsible for strength reduction of the shale which may lead to shear failure of the borehole. Among the clays mentioned previously, montmorillonites are dispersible, may disintegrate, and are hydratable whilst Illites are nonswelling clays in their 'pure' form but have a high tendency to dispersion. However, if generated from the transformation of smectite, illite may exhibit swelling tendency and cause borehole closure in deep intervals (Fink, 2011).

\subsubsection{Brittle Shales}

Brittle shales are quite consolidated rocks but disintegrate to fragments when exposed to water. These pieces do not soften or swell in the water though. Brittle failure is due to: 1) shales becomes weaken due to hydration of micro fracture surfaces, and bedding planes, 2) clay fail when surrounded by a quartz and feldspar matrix which are non-swelling minerals. Brittle shales usually contain a high percentage of kaolinite, illite and chlorite which may become unstable in a high pH environment (Peng et al, 2010). Borehole failure and shape of cuttings, on these occasions, might be very severe depending on the degree of rock anisotropy and the direction of 
drilling with respect to the lamination (bedding planes) dip, which is also known as the attack angle. The best direction of drilling from the field observations is normal to the bedding planes, while wellbores that are almost parallel to the bedding may experience extensive instability issues (Last etal.,1995; Okland and Cook,1998, Brehm et al., 2006).

Brittle shale might also be a source rock for hydrocarbons especially gas resources. However, the success of production under these circumstances depends mainly on the maturity and brittleness of shales which is defined based on elastic properties and minerals dominations. Technically speaking, the larger the brittleness index is, the higher the success of hydraulic fracturing operation would be in developing fracture networks in the shale matrix which would result in significant improvement of the recovery factor from these very tight formations (Gholami et al., 2016).

\subsubsection{Abnormally Pressurized Shales}

Abnormally pressurized regions can be generated because of shales: 1) when the pore pressure is transmitted slowly to shales from surrounded sandstones over geological time. The fluid cannot be expelled from thick shales on these occasions when they are under compaction, causing a significant pore pressure increase in deep intervals and, 2) any sandstone formations interbedded or connected to the shale can generate a pressurized zone if it is completely isolated (Li and Wu, 2015).

Splintery cuttings are often observed at the shakers during drilling through abnormally pressurized shale. These small, thin and sharp pieces of cuttings are produced when the hydrostatic pressure of the drilling fluid is less than the pore pressure in the shales. The pore pressure, under these circumstances, bursts the shale into the wellbore with long, splintery and concave in shape. The wellbore enlargement from this kind of failure would be a complete washout of the wellbore wall and unlike wellbore failure in brittle shales does not take place only in specific directions. In the case of stress anisotropy, there might be more failure in certain directions, but the entire wellbore circumference will still be impacted. As mentioned, this failure is caused by inappropriate selection of the mud weight and can be prevented by increasing the mud weight.

\subsubsection{Tectonically Stressed Shales}

These kinds of shales are often observed in regions with diastrophic movement. Shales in these circumstances are inclined to have oriented bedding planes in the direction of applied stress. This stress causes excessive shear failure within the borehole when relieved. The severity of the failure may increase if the cohesion of bedding planes decreases due to water adsorption. The nature of cementation (e.g., amorphous silica, aluminium or calcium silicate, or organic materials) may also play a crucial role in the stabilization or disintegration of shale formations 
under stress (Pervukhina et al., 2011). Graue, (2011) pointed out the following criteria as the main characteristics of which must be fulfilled to have a tectonically stressed shale:

i. Shales with low mechanical strength, which are undercompacted, and have a low degree of consolidation.

ii. Severe tectonic stress in the area which provides ductile deformation and increases the pore pressures.

iii. Structural culminations to decompact water and hydrocarbons.

iv. Carrier beds for migration of fluids and gases.

Applying chemical inhibitors and/or increasing mud weight may be two possible remedies on such occasions, although they do not appear to be the complete solution. Another possibility in regards to mitigating shale related instability is to seal the formation against the invasion of drilling mud. This can be done by controlling pressure, temperature and filtration properties of water based muds. Blended organic compounds containing an emulsifier and a sulfonated blown asphalt or modified gilsonites can be used, under these circumstances to plug the micro-fractures and pore throats of shale. This may reduce the fluid contact along the fractures and pore spaces, and when combined with other remedies decreases the severity of the problem but it may not completely solve the problem.

\section{Mud Treatment}

\subsection{Oil Based Muds (OBMs)}

Wellbore Instability problems experienced due to hydratable, dispersible, and brittle shales can be partially eliminated by replacing water with oil in the drilling fluid (Patel et al., 2007). In fact, upon using Oil Based Muds (OBMs), in which water is emulsified within the continuous oil phase, shales are no longer exposed to water and can be, partially to totally, stabilized. This is the main reason why OBMs are used for drilling $70 \%$ of all reactive shale formations and are often the best choice for drilling exploration and HPHT wells (Caenn et al., 2011).

The stability of shales during drilling with an OBM is linked to polarity and capillary effects. In fact, due to the wettability between the surface of oil and shale, an OBM has to overcome a huge pressure caused by the capillary effect which is in order of hundreds of PSI. Thus, shale instability with OBMs is normally induced due to insufficient pressure of muds. It should also be noted that even in OBMs, the emulsified water may still act as a semi-permeable membrane and provides a mechanism for osmosis by migrating into shale. This migration may not occur if the salinity level of the mud and the shale formations are equal (Patel et al., 2007). Another issue is the selection of an appropriate density for OBMs to have mechanical stability. Generally, the higher the oil to water ratio is; the lower the density. On the contrary, the higher the oil to water ratio is, the higher the viscosity would be.

It should be noted that although shale inhibition can be maximized when OBMs are used, they have limited applications due to poor data acquisition, high tendency for mud losses in deep 
water drilling, poor biodegradability, contamination of cuttings, special preparation and maintenance costs as well as environmental constrains (Caenn et al., 2011).

\subsection{Water Based Muds (WBMs)}

Three approaches are generally taken to mitigate for the instability problems posed by the interactions between WBMs and shales. They include: 1) ionic inhibition, 2) encapsulation and 3) physical plugging (Anderson et al., 2010). These treatments may be used independently or in combination with others, depending upon the amount and nature of the clays within the shale. The treated WBM may not be as efficient as an OBM, but may have some applications in mitigating shale instability. When any of the above treatments are considered, caution must be taken to have a low-solid and non-dispersed fluid. A good solid control, for instance, helps to maintain the rheological characteristics of the mud and if neglected a significant reduction in the penetration rate and other issues like pipe stuck might be experienced.

\subsubsection{Ion Inhibition}

The interlayer cations which control dispersion within clay lattice and its chemical stability, are exchangeable. In fact, the ionic inhibition is an effective approach to reduce the dispersion of clays in WBMs by exchanging the initially present cations with cations that help to stabilize the shale. The degree of success depends mainly on the type and concentration of inhibitors used but the effect of hydration may not be totally eliminated (Van Oort, 2003).

Surface of clay would establish strong negative surface charges when they are placed in water. As a result, cations included in the mud are adsorbed on these surfaces based on the attraction force created. However, the $\mathrm{pH}$ of the system may dramatically affect these reactions. Potassium and ammonium are the most inhibitive ions used for drilling through shales (Van Oort, 2003). This is mainly because of their diameters, which is very close to the distance between the layers of montmorillonites and illites, their low hydrational energies and small hydrated diameters. Potassium cations often provide a very good performance in shales with a huge amount of illite as they are capable of bringing illite to its pure form which is a non-swelling clay. There are other ion inhibitors which are used under different circumstances including salts, quaternary ammonium potassium formate, saccharide derivatives, sulfonated asphalt, grafted copolymers, Polyoxyalkylene amines, anionic polymers.

Considering the variation of clays and their complex behaviours, the response of a particular shale is almost unpredictable. Thus, in exploration drilling, predictions would be totally based on geological knowledge of the field. In development drilling, cores (sidewalls) are often available and tested to determine the most effective inhibitors. In their absence, recovered cuttings can be used but they may have gone through some alterations because of exposure to the drilling fluid. 


\subsubsection{Chloride}

Highly ionic solutions, particularly those with monovalent anions such as chloride, can severely reduce the rate of water imbibition for smectite clays. The most common and most economical source of chloride $\left(\mathrm{Cl}^{-}\right)$is common salts such as $\mathrm{NaCl}$ and $\mathrm{KCl}$. In offshore applications, this is readily available from sea water (20,000 mg/l) (Fink, 2011). The use of $15-20$ wt\% sodium chloride or 7-10 wt\% potassium chloride in a WBM is very common to improve drilling performance in highly reactive shales.

\subsubsection{Phosphate}

Complexes of phosphate anions can preclude cation exchange and water imbibition in active shales. The most commonly employed forms of phosphate are $\mathrm{PO}^{4-}$ and $\mathrm{P}_{2} \mathrm{O}^{7-}$. Anti-bit balling additives are often phosphate surfactants due to their inhibitive characteristics. Most of phosphates have a temperature limit of $65^{\circ} \mathrm{C}$ but $\mathrm{Na}_{2} \mathrm{HPO}^{2-}$ can be used up to $200{ }^{\circ} \mathrm{C}$ (Caenn et al., 2011).

\subsubsection{Aluminates}

Aluminate systems stabilize shales by precipitating and gelling aluminate complexes in shale pores, blocking hydraulic flow and building osmotic membranes. Both laboratory and field data on their merits are ambiguous and the use of these systems are not widely recommended (Caenn et al., 2011).

\subsubsection{Methylglucoside}

Methylglucoside is a modified saccharide which generates osmotic pressures and impact a high viscosity on mud filtrates. The system has been used on several occasions in the field with mixed results (Fink, 2011). A high concentration of methylglucoside is required to achieve sufficient efficiency which would probably be expensive and difficult to provide.

\subsubsection{Cationic Polymers}

Inhibitive drilling fluids based on cationic polymers were developed and used in the late 80s/early 90s. They offer good cutting transportation poor wellbore stability due to mud pressure penetration and shale hydration without retardation. The cationic polymers are expensive and a high screen-out rate on shale, causing operation to be expensive and logistically challenging (Fink, 2011). Cationic polymers have been successfully used in South America and in some other locations, worldwide but they cannot be used in the presence of chloride in drilling muds.

\subsubsection{Amphoterics}

Amphoterics are dual-charge systems that have recently been proposed for shale stabilization. Their primary mode of action is inhibition, i.e. control over shale hydration through adhesion at clay sites, which should generate a hydrophobic layer. Good preliminary results have been 
obtained in the Gulf of Mexico, where the systems showed effective inhibition of gumbo cuttings (Caenn et al., 2011). These systems, however, have no impacts on the mud pressure penetration and as such do not provide a solution for time-dependent shale and borehole destabilization problems.

\subsubsection{Encapsulation}

Cuttings from reactive shale formations require protection during their journey to the surface. They are subjected to considerable forces and grinding action in the annulus during circulation. This protection must be deployed rapidly to prevent any further degradation of cuttings exposed to water based mud. A common strategy is to use long chain polymers, such as Partially Hydrolysed Polyacrylamide (PHPA), that adhere to the cuttings surfaces, slow the imbibition of water and allow them to maintain their sizes. If the encapsulation polymer is successful, the cuttings coming over the shakers are firm and not sticky (Zengeni et al., 2012). However, application is limited to those shales producing medium to hard cuttings during drilling.

It should be noted that in order to be effective, a sufficient amount of encapsulation polymer must be present in drilling fluids at all time. The concentration needs to be measured and replenished as the amount of polymer in the mud decreases over time. This is mainly because

soft shales tend to mechanically disintegrate easily, and small particles will take up polymers rapidly (Mballa et al., 2013).

\subsubsection{Physical Plugging (Blocking Agents)}

Pore pressure increase close to the wellbore wall is one of the major mechanisms causing shale failure. The differential pressure between the drilling mud and the pore fluid creates a filter-cake on the borehole wall in permeable formations, which prevents further invasion of mud. However, shales are almost non-permeable formations with a permeability of $10^{-6}$ to $10^{-12}$ Darcy. On this occasion, filter cake cannot be generated with mud pressure applied directly on the formation, causing slow penetration and invasion of mud into the shale. This slow pore pressure increase reduces the mud support and increases the rock stress around the wellbore, which ultimately causes excessive rock failure. Under these circumstances, ionic inhibition and encapsulation may not totally work and physical plugging of pore throats might be the best option (Akhtarmanesh et al., 2013). Thermally activated polyglycol are perhaps the best option under these circumstances. Their molecules are normally stable in a drilling fluid at surface conditions. Once the temperature passes a critical point, the polyglycol generates hydrophilic and hydrophobic phases. The transition temperature is called the cloud point which can be regulated with specific types of polyglycol and adjustments of mud salinity. The resulting micro-gels are large enough to block the shale pore throats and stop pressure transmission. However, there are many additives which may affect the cloud point transition. The correct cloud point has to be carefully engineered in the laboratory and a sufficient concentration of glycol must be present in the 
drilling fluid. The glycol concentration also needs to be monitored in the field as the glycol is depleted over time.

Asphaltenes and Gilsonite are other options to block the pore throats of shales and their microfractures. However, they need to be combined with suitable Loss Circulation Materials (LCM) to reduce filtration loss into the fractures (Metin et al., 2013). Materials which can be purely dissolved in water might be a good choice for treatment of brittle shales under these circumstances. However, when the situation becomes severe, none of these physical plugging materials may be appropriate with the only remaining option is to use OBMs.

\section{Mud Additives}

There have been many shale inhibitors proposed in the past decades, many of which were not totally successful either because of complicated nature of clays or their cost and environmental issues. Many of these inhibitors, especially the polymer ones, have also revealed functionality/integrity issues under different pressure, temperature and $\mathrm{pH}$ conditions. In this section, the technical selection criteria conventionally used to select an inhibitor for WBM drilling under different conditions are presented.

\subsection{Technical Selection Criteria}

There are generally many criteria involved in the selection of a specific additive as an efficient shale inhibitor for WBMs. These criteria include, but are not limited to (Mitchell and Miska, 2011):

I. Fluid Invasion: Minimum petrophysical log interferences and reservoir impacts

II. Filter Cake: Minimum differential sticking

III. Lubricity: Minimum energy loss

IV. Environment: Non-toxic and safe

V. Temperature: Tolerant to the expected downhole and surface temperature

VI. Compatibility: No adverse reaction with other additives

VII. Contamination: Tolerant of expected contamination

VIII. Ease of Use: Minimum manpower

IX. No Lumping: Minimum utilization

X. Rapid Mixing: Fast preparation in emergency

\subsection{Conventional Drilling Conditions}

There have been many inhibitors developed for a conventional drilling in which the temperature and pressure may not exceed $150{ }^{\circ} \mathrm{C}$ and $70 \mathrm{MPa}$ respectively. A few of these inhibitors are discussed in this section.

\subsubsection{Potassium Chloride ( $\mathrm{KCl})$}

Traditionally, salts are used to reduce the hydration of shales by the exchange of cations. Potassium chloride is one of the earliest chemicals used as an inhibitor of water sensitive shales 
(Qu et al., 2009). In WBMs, potassium cations of $\mathrm{KCl}$ can effectively saturate the surface of shale and mitigate against the swelling and dispersive tendencies. In this process, the cation of potassium is compacted by the tetrahedral sheets of clays and covers its surface. As a result, potassium creates a strong bond with anions on the surface, preventing further hydration of clays. Besides, it is closely held in the clay lattice and does not get to the repulsive forces required for dispersion. However, to provide a good efficiency, a high concentration of KCL is required to be added to WBMs which has a negative impact on the environment and wireline logging measurements (Guerrero and Guerrero 2006; Zhong et al. 2013; Caenn et al., 2011). This is due to the significant amount of chloride ion which remained in the mud solution after interaction of $\mathrm{KCl}$ with clays (Suter et al. 2011).

There have been a few recommendations to combine $\mathrm{KCl}$ with other additives, such as Polymers (Qu et al. 2009) or PHPA (Suter et al. 2011) in order to reduce the concentration of salt in WBMs. However, the search continues to replace $\mathrm{KCl}$ with other suitable inhibitors. Table 2 gives a few of the inhibitors developed and used in 1990s to stabilize the boreholes crossing shale formations.

\subsubsection{Calcium Chloride $\left(\mathrm{CaCl}_{2}\right)$ and Formates}

The mechanisms through which $\mathrm{CaCl}_{2}$ based muds stabilizes shale include (Devereux, 1998):

- Osmotic dehydration: Elevated levels of $\mathrm{CaCl}_{2}$ salt reduces the water activity of the drilling fluid with respect to shale pore-fluids, such that an osmotic force is generated between the shale and the drilling fluid. This force would dehydrate the shale and partially offsets the hydraulic invasion of filtrate into the shale driven by the pressure overbalance, which may cause cuttings and wellbore instability.

- Membrane building: The osmotic process mentioned above is not totally effective, i.e., the membrane system acts as a "leaky membrane" allowing solutes/ions to pass from the drilling fluid to the shale and vice versa. The osmotic process is amplified by increasing the membrane efficiency. This is achieved by the use of glycols in the mud which attaches to clay surfaces and restricts the free transport of solutes.

- Ion Exchange: Additional help in preventing destabilization of clay-rich shale is offered through inhibition of swelling clays by $\mathrm{Ca}^{2+}$ ions. These ions may displace mono-valent ions on clay surfaces and thereby reduces the swelling stress/pressure acting between clay platelets.

- Encapsulation: Further inhibition is offered by the use of encapsulation polymers in $\mathrm{CaCl}_{2}$ based water based muds. These polymers have a specific affinity for clay surfaces, and can be adsorbed by them. This adsorption aids in preventing dispersion into the colloidal suspension (Caenn et al., 2011).

$\mathrm{CaCl}_{2}$ based muds are cheaper than synthetics and able to provide excellent cuttings and wellbore instability together with excellent lubricity. However, they are more expensive than conventional 
WBMs, require close attention on good solid removal practices and are not as environmentally friendly as WBMs (Smith, 2009).

\subsubsection{Lime/gypsum/lignosulphonate}

Lime, gypsum/lignosulphonate muds are originally introduced to prevent shale dispersion. Their main shale stabilization mechanism is inhibition through ion exchange. Using inhibitive ions such as $\mathrm{Ca}^{2+}$ and $\mathrm{K}^{+}$, the swelling pressure between the clay platelets is reduced, decreasing dispersion tendencies. These additives are cheap and their mud is easy to maintain but they tend to disperse shale formations and cuttings causing further wellbore instability. They also suffer from high dilution rates and may not be economically feasible in that sense (Devereux, 1998).

\subsubsection{Organic Amines}

Guerrero and Guerrero (2006) concluded that amines are effective inhibitors and can be as efficient as potassium based salts, $\mathrm{KCl}$. Different organic amines were studied ever since and classified into three major categories of monocationic, oligocationic and polycationic, according to their structure and chemistry (Patel, 2009).

Monocationic amine can be used to mitigate against environmental issues such as marine toxicity and biodegradability, but they have limited applications for shale instability related issues due to their limited temperature stability. Oligocationic amines were then introduced providing more permanent clay stabilization because of simultaneous cationic absorption. In fact, the unique molecular structure of the oligocationic amine allows cations to enter the clay platelets and bind the platelets together. As a result, water can no longer be absorbed by clays, resulting in extensive shale stabilization in the aqueous system of drilling. Polyethoxylated diamines, polyether amines, polyethylene amine salts and ether amines are few examples from oligocationic amine family which can be used as a shale inhibitor (Zhong et al. 2015).

Unlike oligocationic amines, polycationic amines, as the last member of organic amines, have a large molecular size and are unable to go through the shale layers effectively. As a result, they have a limited application in stabilizing shale formations. They also increase the viscosity and toxicity of muds and are not very well recognized inhibitors.

\subsubsection{PHPA/Amine Combination}

Partially hydrolysed polyacrylamide (PHPA) polymer was introduced as a polymeric swelling inhibitor to improve shale stability (Khodja et al. 2010). PHPA is a water-soluble anionic synthetic polymer and is known to be a mechanical inhibitor due to its high molecular weight, which can physically block the capillary network on the shale surface. Due to this large molecular size, it is unable to penetrate into shale layers and provide a total stabilization. As a result, PHPA is often combined with an organic amine to have a chemical inhibition through the low molecular weight of amine and the high molecular weight of PHPA (Guerrero and Guerrero, 2006). The inhibition 
mechanism can then be explained as a two stage process in which: 1) the low molecular weight amine penetrates into the shale layer efficiently and holds the layers together, preventing further hydration, and 2) PHPA provides an external absorption, acting as a protective coating on the shale surface reducing the slow invasion of muds into shale layers (Retz et al. 2006).

The amine/PHPA system has the advantages of being a very low toxic and biodegradable additive, but it can be harmful to human health due to degradation of acrylamide into ammonia and the residual amount of acrylamide monomers in WBMs (Patel et al. 2007).

\subsubsection{Salt/Polymer (PHPA)}

Salt/polymer drilling fluids were introduced in 1970s and offered a step change in the improvement of shale stabilization. Their main stabilization mechanisms are (Devereux, 1998):

- Inhibition through ion exchange where the swelling pressure between the platelets is reduced, decreasing the dispersion tendency.

- Inhibition through encapsulation where high molecular weight polymers such as PHPA prevents the dispersion of clays.

These additives are relatively inexpensive while their mud is easy to maintain and environmentally friendly. However, WBMs with these additives have no tendency to counteract filtration and pressure invasion which is the main reason why borehole instability is experienced once this type of muds are used and remained in the open-hole for a long period of time (Patel et al. 2007).

\subsubsection{Hexamethylenediamine (HMDA)}

Hexamethylenediamine (HMDA) is a known alkyleneamine with applications for the shale swelling problem. It can be as efficient as potassium chloride with the advantage of reducing water hydration by filling the gaps between the interlayers of clays. Once added to WBMs, HMDA can act as a non-ionic additive creating a negative polarity which modify the surface of active clays. The surface modification causes the clay particles to stick together and prevent further hydration of shale (Chamberlain et al., 2002). HMDA is biodegradable with a low level of toxicity but has a big chain of diamines avoiding its total solution into water. This has resulted in its limited application in effectively inhibiting shale swelling issues.

\subsubsection{Bis (hexamethylene) triamine (BHMT)}

Bis (hexamethylene) triamine (BHMT) has been introduced as an efficient shale inhibitor according to its molecular structure design (Zhong et al. 2013). Once used as an inhibitor in WBMs, the positively charged ammonium ions neutralize the anions located on the shale surface. In this mechanism, hydrogen bonds are formed between the amine groups and the electrostatic force influences the hydration inhibition (Zhong et al. 2013). The interaction between the electrostatic force and hydrogen bonds breaks the hydrated structure of shale, brings the 
monolayers of clay together and prevents water from entering into the shale. As a result, the adsorption of BHMT provides a hydrophobic condition for the shale surface and reduces the water molecules from entering the shale, thereby inhibiting swelling. BHMT is generally a good shale inhibitor, but its application for HPHT condition has not been reported yet.

\subsubsection{Poly (oxypropylene)-amidoamine (POAA)}

Poly (oxypropylene)-amidoamine appears to be an excellent clay inhibitor as a synthetised polymer developed by Zhong et al., (2012). The advantage of POAA is its molecular structure and low molecular weight. POAA can inhibit swelling based on the monolayer arrangement of polycations in the interlayer of shales. In order to inhibit water absorption, POAA interacts with the clay surface into relatively hydrophobic state, and reduces the hydration and swelling of shales (Zhong et al. 2012). This inhibitor was tested under different conditions and it was concluded that hydrogen bonds between amide and siloxane groups together with the electrostatic force and van der Waals interactions are the main factors behind the reduction of shale swelling and dispersion issues.

\subsubsection{Oligo (Poly-L-lysine)}

Oligo (Poly-L-lysine) (OPLL) is another shale inhibitor presented recently as a high performance biodegradable (i.e., environmental friendly inhibitor which can provide a good performance under a high temperature (up to $180^{\circ} \mathrm{C}$ ) and $\mathrm{pH}$ (7 to 10) conditions) inhibitor. The excellent performance of OPLL was attributed to the synergistic effects of the inhibition of the montmorillonite crystals and the weakening of the diffuse double layer repulsion between clay particles. The results obtained from performing linear swelling and shale dispersion tests indicated that this inhibitor has an outstanding performance in montmorillonite and illite rich shales (Xuan, 2015).

\subsubsection{Henna Extract}

Henna extract was the first plant-based clay stabilizers proposed by Moslemizadeh, (2015). It is an eco-friendly inhibitor and capable of mitigating shale swelling by generation of hydrogen bonding between the hydroxyl groups of Henna extract constituents and oxygen atoms on the clay surface. There have been few drawbacks reported to the application of this inhibitor such as having a low adsorption isotherm in a high $\mathrm{pH}$ environment (i.e., $\mathrm{pH}=9$ ) and deflocculation at low concentrations. Henna extract was also tested only in a low temperature condition and as such there is no record of its application in a HPHT environment. 
Table 2: Few inhibitors used to stabilize shale formations in 1990s (Modified after Fink, 2011)

\begin{tabular}{|c|c|}
\hline \multicolumn{1}{|c|}{ Additives } & References \\
\hline Polymer lattices & Stowe et al. (2002) \\
\hline Hydroxyaldehydes or hydroxyketones & Westerkamp et al. (1991) \\
\hline Polyols and alkaline salt & Hale and van Oort (1997) \\
\hline In situ crosslinking of epoxide resins & Coveney et al. (1999) \\
\hline Quaternary ammonium carboxylatesBD, LT & Himes (1992) \\
\hline Quaternized trihydroxyalkyl amineLT & Patel and McLaurine (1993) \\
\hline Poly(vinyl alcohol), potassium silicate, and potassium carbonate & Alford (1991) \\
\hline Copolymer of styrene and substituted maleic anhydride (MA) & Smith and Balson (2000) \\
\hline Water-soluble polymers with sulfosuccinate derivative-based & Alonso-Debolt and Jarrett \\
\hline surfactants, zwitterionic surfactantsBD, LT & (1995) \\
\hline
\end{tabular}

\subsection{HPHT Conditions}

Drilling under HPHT conditions has gained a lot of attention in recent years due to demands for energy supply. However, stability of wellbores under these harsh and hostile environments has been a major challenge in front of the oil and gas industry. OBMs can be a solution under these circumstances but regulations and environmental concerns may not be in favour of using this kind of mud. As a result, WBMs have been considered as an alternative option even for HPHT conditions. However, there are only few shale inhibitors developed for formulation of WBMs under such conditions which indicates the need for further studies in this area of research.

\subsubsection{Polyoxyalkyleneamine (POAM)}

Qu (2009) proposed the use of polyoxyalkyleneamine (POAM) for inhibiting shale swelling. They did a lot of tests, including rheological parameters determination, dispersion tests, biological toxicity and compatibility test to ensure that POAM is a good choice for drilling through troublesome formations. The results obtained revealed that this inhibitive agent does not change the rheology of drilling fluids and is indeed an environmental friendly agent.

To inhibit shale hydration and swelling, many of water-soluble polymers have been used but most of them have a poor performance in harsh situation such as high salinity and temperature conditions. Jianga et al., (2015) introduced a new water-soluble copolymer for stabilizing shales. They combined acrylamide (AM), acrylic acid (AA), mono-2-0-(allyloxy-2-hydroxyl-propyl)- $\beta$ cyclodextrin (O- $\beta-C D$ ) and allyl alcohol polyoxyethylene ether (APEG) to create a new copolymer. They evaluated its applications through salt-tolerance test and thermogravimetric-differential scanning calorimetry-mass spectrometer analyses. The results obtained indicated that this polymer has a high hydration inhibitive performance and can maintain the hardness of shales even under high salinity and high temperature conditions. 


\subsubsection{Zizyphus Spina-Christi Extract (ZSCE)}

Zizyphus spina-christi extract (ZSCE) is another non-ionic surfactant inhibitor proposed recently by Shadizadeh et al., (2015). The inhibition mechanism was linked to the adsorption of the hydrophilic part of the surfactant on the surface of clays and orientation of hydrophobic tail toward the aqueous phase. It appeared to be compatible with conventional WBMs but it was not able to provide a good efficiency above a critical micelle concentration (CMC).

\subsubsection{Dopamine (DA)}

Xuan et al. (2013) evaluated the application of dopamine (DA) as a potential shale inhibitor. The results obtained from bentonite dispersion and linear swelling tests indicated that DA can be an excellent shale inhibitor. The mechanism of this inhibition is based mainly on coating of polydopamine in the interlayers of montmorillonite. The DA is thermally stable and can withstand the temperature of up to $200^{\circ} \mathrm{C}$.

\subsubsection{Latex particles and Aluminium Complexes}

Liu et al. (2015) proposed a latex particle and aluminium complexes for shale stabilization. The latex particles are in spherical shape with a size distribution of $80-345 \mathrm{~nm}$. Aluminium complexes were synthesized from the complex reaction of humic acid with sodium aluminate in an alkaline aqueous medium of aluminium hydroxide. The efficiency of this inhibitor was investigated by pressure transmission and membrane efficiency techniques at the operating temperature and pressure of $150^{\circ} \mathrm{C}$ and $50 \mathrm{MPa}$ respectively. It was indicated that Latex particles synergistically plug micro-nano scale pore throats by internal bridging while aluminium complexes chemically precipitate from filtrate to plug the pore throat.

\subsubsection{Cetyltrimethylammonium bromide (CTAB)}

Clay minerals are negatively charged and because of the electrostatic attraction, cationic surfactants are strongly adsorbed on their surfaces. Anionic surfactants are often adsorbed at the positive sites at the edges of clay crystals. Nonionics, on the other hand, compete with water for adsorption on the basal surfaces of clays and limit the expansion of clays (Foster and Waite 1956).

Cetyltrimethylammonium bromide (CTAB) is a cationic surfactant with various applications in the petroleum industry ranging from enhanced oil recovery to flow assurance remediation problems. Moslemizadeh et al. (2016) investigated the inhibition capability of CTAB and indicated that montmorillonite surfaces modified by CTAB losses their affinity for water. In other word, CTAB inhibits montmorillonite from swelling by preventing water adsorption on its surface. The WBM designed by adding CTAB was also thermally stabile and could be used for HPHT conditions. 


\subsubsection{Silicates}

Silicate based drilling fluids react with divalent ions (e.g., calcium and magnesium) in the shale and form a scaly precipitate which inhibits further hydration. They can be very effective and successful when drilling through reactive shales. However, they need an experienced drilling fluid engineer on site to avoid common problems associated with them such as bit balling and accretion $^{1}$ onto the Bottom Hole Assembly (BHA). Silicates are not recommended when drilling highly inclined hole (i.e., above 30 degree) since it increases the torque on bit significantly. Thus, they must be used when an influx of divalent ions such as calcium and magnesium is expected because silicate will form a non-permeable gel when is in contact with these ions (McDonald et al., 2007).

The mechanisms by which silicates stabilize shale formations are:

- Pore plugging: Soluble silicate solutions starts out as mono-silicate, that partially polymerises to form negatively charged silicate oligomers. The process is halted at the $\mathrm{pH}$ of 11-12 due to mutual repulsions, leaving oligomers which are still small enough to penetrate into the shale's micro-pore structures by hydraulic flow or diffusion where:

I. Pore fluid $(\mathrm{pH}+/-7)$ dilutes the filtrate whereby the oligomers overcome their mutual repulsion and coagulate to form silicate gels.

II. Oligomers react with free polyvalent cations associated with the shale/clay surfaces to form insoluble precipitates.

III. The gelled and/or precipitated silicates provide a physical barrier which prevent further filtrate invasion and pore penetration. Thus, the wellbore and shale are pressure isolated and stabilized.

- Osmotic dehydration: The barrier of gelled/precipitated silicates also acts as a highly selective osmotic membrane. As a secondary mechanism to stabilize shales, elevated level of solutes can be used to reduce the drilling fluid's water activity. This generates an osmotic pressure driving osmotic flow of waters across the silicates membrane from the shale to the drilling fluid. Although the amount of water is minimal, this process will dehydrate the near-wellbore shale effectively because dehydration leads to larger near wellbore effective stresses and an increase in shale strength, both of which are beneficial to stability (Alford et al., 2005).

- Ion Exchange: an additional advantage of monovalent ions such as $\mathrm{K}^{+}$is that they can be exchanged by $\mathrm{Ca}^{2+}$ and $\mathrm{Mg}^{2+}$ at the clay surface, making these ions available to precipitate. The high salinity level of the solution decreases silicate gelation time and accelerates the deposition of silicate gels (Fritz and Jarrett, 2007).

Silicate based WBMs are cheaper than synthetics and can provide excellent wellbore stability, good metal/shale and metal/sandstone lubricity (McDonald et al., 2007). They are also

\footnotetext{
${ }^{1}$-The formation of a hard and thick deposit of shale on the BHA.
} 
environmental friendly and less prone to bit balling which is required to have a high rate of penetration (ROP). However, they are more expensive than conventional muds and require attentions on good hole cleaning practices. The WBM having silicates can be as heavy as $14 \mathrm{ppg}$ with a temperature limitation of $225^{\circ} \mathrm{F}$ (Soric et al., 2004).

Knowing the limitations of conventional silicates based muds, nano-materials were taken into consideration as a revolutionary method to design new smart drilling muds for different drilling operations. Nanosilica has been used for stabilizing invert emulsion drilling muds in HPHT operations with potential of inhibitive even at low concentrations (Amanullah and Al-Tahini, 2009). The nano scale size and high surface area of nanosilica makes it a strong and reactive additive as a shale inhibitor (Alias et al., 2014). These nanoparticles also have a high thermal stability, and are affinitive to acidic gases such as $\mathrm{H}_{2} \mathrm{~S}$ and $\mathrm{CO}_{2}$. Nanosilica added to WBMs is capable of sealing the nanoscale pores and reducing the invasion of mud into shale formations. Due to the high concentration of silica (silicon dioxide), nanosilica can also enhance the strength of shales and reduce the pore pressure increase due to mud filtration. These characteristics of nanosilica may help the industry to overcome the technical challenges of deep sour gas drilling and geothermal operations.

Aftab et al., (2016) used five different additives including potassium chloride $(\mathrm{KCl}), \mathrm{KCl} /$ partial hydrolytic polyacrylamide (PHPA), $\mathrm{KCl} /$ graphene nanoplatelet (GNP), $\mathrm{KCl} /$ nanosilica and $\mathrm{KCl} /$ multi-walled carbon nano-tube (MWCNT) into water based mud to evaluate their applications on shale stability. They indicated that KCL/PHPA is the best in terms of shale swelling which was an obvious conclusion but they did not provide a good discussion on the effect of surface charges and complication of interactions posed by added nanoparticles. They also reported a poor performance from nanosilica, which might be due to repulsive force induced by the negative surface charges of nanosilica and clays. It should also be noted that nanosilica is more like a pore plugging agent and may not have the same efficiency as KCL/PHPA when it comes to ion inhibition.

Elochukwu et al., (2017) did a series of Zeta Potential (ZP) measurements under different pH conditions on water based mud samples having bentonite and nanosilica. They pointed out that like silicate, nanosilica additives decreases the cutting carrying capacity of drilling fluid by reducing the yield point. Therefore, a careful monitoring of solid carrying capacity and removal on surface would be required. A cationic surfactant was recommended to modify the surface charge of nanosilica and an approach was presented to ensure that rheology and other properties of muds are not disturbed by this modification.

\subsubsection{TAME-Polyglycol}

Thermally activated mud emulsion (TAME) fluids are solutions of so called "polyglycols" in water. These polyglycols are non-ionic surfactants with water-repelling (hydrophobic) and water-loving (hydrophilic) parts (Downs et al., 1993). 
The polyglycols used in TAME formulations are characterised by their inverse solubility in water. They are typically miscible with water at lower temperatures but, when heated, will eventually separate into a second distinct liquid phase as the polyglycol becomes partially insoluble in the aqueous phase. The temperature at which this starts to occur is defined as the "Cloud-Point" or "Cloud-Point Temperature (CPT)". TAME based muds stabilises the shale through the following mechanisms (Downs et al., 1993; Van Oort et al., 2003).

- Inhibition through ions exchange: Using inhibitive ions, the swelling pressure between the clay platelets is reduced, causing reductions in dispersion tendencies.

- Inhibition through glycol displacing water at clay surfaces: The swelling pressure is reduced when water is displaced by glycol molecules.

- Reduction of water flow into shales through enhanced mud filtrate viscosity: TAME polyglycols viscosify the filtrate of the mud to some extent and therefore decelerate the rate of fluid invasion and pressure elevation by the same factor, lengthening the timescale for stability problems.

- Reduction of water flow into shales through the TAME effect: By virtue of their ability to cloud-out and form high viscosity emulsion, TAME polyglycols can block shale pores, thereby reducing shale permeability and restricting fluid invasion. A TAME drilling fluid is designed such that it coincides with the bottom hole circulation temperature (BHCT). This solution invades the shale under the influence of hydraulic and diffusion gradients and experiences temperature elevation due to the high bottom-hole static temperature (BHST). Temperature induced phase-separation occurs and emulsion is formed in-situ, filling the pores. Possibly, phase separation forces the polymers onto the clay surfaces, coating them and changing their wettability. Polyglycols deposited in-situ now acts as a barrier that restricts further fluid invasion and mud pressure penetration.

TAME based drilling muds are cheaper than synthetics and they are perhaps the best of inhibitors. They are also easy to maintain with a very good temperature stability to up to $300{ }^{\circ} \mathrm{F}$ (Downs et al., 1993). They are, however, more expensive than the conventional WBMs and require close attentions on good hole cleaning practices.

\section{Water Based Mud Design}

In this section, steps that are often taken to characterize shale formation for a suitable mud design is presented and discussed in details. This is the same procedures exercised by the industry for WBM selection.

\subsection{Shale Sample Characterization}

Shales formations encountered in different intervals during drilling must be characterized to evaluate their swelling and dispersion tendencies. As a result, cuttings, cavings, side wall or full diameter cores of shales are examined with different techniques to indicate their beddings, 
sedimentary structures, colours, fractures and consolidation levels as well as major clay minerals (Stephens, 2009). Few of the most famous techniques used at this stage are presented below.

\subsubsection{X-Ray Diffraction (XRD)}

$X$-Ray diffraction (XRD) is a technique commonly used to identify type of minerals included in the shale composition. The apparatus works based on rotating the shale sample and simultaneously bombarding it by $x$-ray beams. The crystalline structure of minerals diffracts the $x$-ray beam with their own identical features which will be detected by the apparatus. The XRD technique can be supplemented with a clay fraction analysis to improve quantification of the clay minerals within the bulk sample.

\subsubsection{Thin Section Analysis}

Thin section analysis technique uses a specialized petrographic transmitted light microscope equipped with a rotating stage and a polarized light analyser to measure the optical properties of crystalline materials. A standard 30-micron thick section of a shale sample is mounted on a glass slide and descriptive/qualitative information including texture, mechanical support structures, organic materials, micro fractures and pores are recorded.

\subsubsection{Scanning Electron Microscope (SEM)}

Scanning electron microscope provides a high resolution and magnified images of the shale structure. It can give a better 3-Dimension analysis of micro fractures and pores compared to a transmitted light microscope used for the thin section analysis. The combination of the energy dispersive X-Ray fluorescence detector (EDAX) with a SEM improves the results by giving the chemical composition of samples. The integration of the SEM and EDAX also help to characterize composition, size and shape of pores, mineral contents, and mineral imbedded in the sample matrix.

\subsection{Physico-Chemical Analysis}

At this stage, attempts are made to evaluate the physical and chemical parameters of shale samples including their density, water content and exchangeable cations. Mechanical tests including triaxial compressive tests are also done to determine the mechanical behaviour and the maximum strength of samples.

\subsection{Reactivity Quantification}

Few tests including water adsorption, dielectric constant, Methylene blue index and capillary suction time are carried out at this stage. Few of these tests are discussed in this section.

\subsubsection{Water Adsorption}

The water activity of shale can be measured by the use of a special hydrometer, which measures the relative humidity of the sample. The relative humidity is then expressed in percentage to give 
water adsorption (Chenevert, 1970). There is another way of measuring water adsorption based on conductivity which was presented by Pezhman et al., (2016). According to them, a fine ground shale sample is allowed to equilibrate for a specified duration when it is placed in water. The amount of adsorption is then measured which would be high for reactive shales.

\subsubsection{Cation Exchange Capacity (CEC)}

Cation Exchange Capacity (CEC) test measures the exchangeable cations on the surface of clays. As mentioned earlier, clay particles have negative surface charges which can be satisfied with exchangeable cations with a positive surface charge such as $\mathrm{Na}^{+}, \mathrm{Ca}^{2+}, \mathrm{Mg}^{2+}, \mathrm{K}^{+}$. The CEC measurement follows the API recommended methylene blue (MB) capacity test (API 13I, 2004). In this test, finely grinded pieces of shale are dispersed in water with a minor amount of dispersant, sulfuric acid and hydrogen peroxide. The mixture is boiled, cooled to room temperature and titrated dropwise with a methylene blue solution. The titration endpoint is reached when a drop of the mixed sample is placed on a filter paper, resulting in a faint blue halo surrounding the dyed solids (Stephens et al., 2009). The CEC is then measured in milliequivalent per $100 \mathrm{~g}$ of clay (meq/100g) and values are often greater than $20 \mathrm{meq} / 100 \mathrm{~g}$ for reactive clays and $10-20 \mathrm{meq} / 100 \mathrm{~g}$ for moderately reactive clays. It should be recalled that the CEC of a typical smectite is between 80 to $120 \mathrm{meq} / 100 \mathrm{~g}$.

\subsubsection{Capillary Suction Time (CST)}

Capillary Suction Test (CST) measures the time it takes for a clay/shale slurry to travel a given distance. The test requires $3 \mathrm{~g}$ of dry shale sample per test. Flocculation as a result of shale dispersion into the inhibitive fluid reduces the CST. As a rule of thumb, reactive shales with a high smectite clay content have a high CST value.

\subsection{Swelling, Dispersiveness and Hardness Testing}

Having obtained the required characteristics of shales, suitable additives are chosen for WBM design (Lal, 1999). These additives must inhibit the clay surface from hydration and minimize fluid entry into pore throats. Initial tests such as swelling, dispersion and bulk hardness together with many other tests such as stability, inhibition and solid tolerance are then carried out to evaluate the performance of the mud designed. These tests are briefly explained in this section.

\subsubsection{Swelling}

Swelling test is a conventional test conducted using a linear swelling tester. Pellet of dry shales are prepared by compression at a high pressure. The pellet sample is then placed in a chamber where it is exposed to water and its volume expansion can be monitored routinely. The percentage of the volume expansion indicates the water-sensitivity of shales. 


\subsubsection{Dispersion}

The dispersion test is often referred to as a screening method for evaluating the application of a shale inhibitor in WBMs. The test involves exposing a measured quantity of shale samples to the inhibitor fluid while the sample undergoes into a mild agitation with the fluid in a roller oven cell. The roller oven agitation is set for 16 hours at $150^{\circ} \mathrm{F}$. After cooling the sample to the room temperature, a 50-mesh sieve is used to recover the shale sample which are further washed and dried at $210^{\circ} \mathrm{F}$. The dried sample is re-weighed to determine the recovery percentage. The difference between the weight before and after the test is used as the indication of dispersed shale (Zhou et al., 2015).

\subsubsection{Bulk Hardness}

Bulk hardness test is used to evaluate the efficiency of an inhibitor fluid when it is exposed to active shale. It measures the hardness of samples after being exposed to an inhibitor fluid. The test involves hot rolling fine sized shale pieces in the inhibitor fluid for 16 hours at $150^{\circ} \mathrm{F}$, recovering shale pieces on a 50 -mesh sieve and placing them into a bulk hardness tester. Torque wrench is used to compress the samples providing the maximum torque required to compress them. Hard shales will have a high torque reading whilst a soft shale dispersed into water gives a low torque reading.

\subsection{Stability Testing}

The main purpose of the Pore Pressure Transmission (PPT) test, which is also known as stability test, is to evaluate the borehole stabilization of a drilling fluid. As mentioned earlier, pore pressure penetration into the shale matrix, reduces the mud support near the wellbore region causing wellbore instability. This pore pressure transmission is measured in the lab by increasing the pressure at the downstream of a shale core sample to push the fluid into the pore space. Any sign of pressure building up at the downstream of the core sample indicates that the fluid invasion is taking place (Stowe et al., 2001; Ghanbari and Naderifar, 2016).

\subsection{Inhibition Testing}

This test evaluates the inhibition efficiency of a shale inhibitor by measuring the yielding of clays and rheological changes of the WBM. The concept of the test is to simulate the gradual incorporation of yielding clays into WBMs. The test determines the maximum amount of bentonite which can be inhibited by $8.0 \mathrm{lb} / \mathrm{bbl}$ treatment of an inhibitor over the period of several days. The sample is aged at $150^{\circ} \mathrm{F}$ for 16 hours, the rheology is measured and the procedure is repeated. The addition of bentonite into the WBM sample and its aging continues until the sample becomes too viscous (Patel et al., 2001).

Incompatibility of additives, such as precipitation, phase separation, and changes in $\mathrm{pH}$, colour or viscosity, can be investigated by mixing and heating the treatment fluids including all additives 
to the required temperature. A pressurized see-through cell is available for evaluation at high temperatures.

\subsection{Solids Tolerance}

\subsubsection{Solid Tolerance}

At this very last step, solid tolerance (contamination) and accretion potential are assessed to ensure that the designed mud can maintain its integrity after contamination without inducing any bit balling issue during circulations. In the solid tolerance tests, the designed mud with its shale inhibitors are hot rolled with different solid contaminants including gypsum, anhydrate, lime or sea water and changes in its rheology, weight, $\mathrm{pH}$ and filtration control are evaluated.

\subsubsection{Accretion Test}

An accretion test investigates the sticking tendency of shales when they absorb water and reaches their plastic limits (Sashikumar et al., 2011). This test is done using a rolling bar which is placed at the centre of a stainless steel test cell. The test cell is filled with a drilling fluid and a pre-weighed sized shale pieces distributed evenly around the rolling bar. The cell is then filled with the testing fluid, sealed properly and placed in a horizontal position in a roller oven where it is rolled for a certain period at the atmospheric condition. Upon rolling, the bar is removed while the excess fluid on the bar is carefully washed. The accreted solid on the bar are scrapped off, dried at $210^{\circ} \mathrm{F}$ and weighed. Accretion is then calculated by the weight of clay solid adhered to the body of the rolling bar, and the result is expressed in percentage.

\section{Conclusions}

In this paper, attempts were made to provide a comprehensive review on different aspects of shale-water based mud interactions. Different kinds of clays/shales were introduced and their sensitivity to water was presented. Certain approaches which are often taken by the industry to treat water based muds were brought and their applications were emphasized to indicate how and when they must be used to receive a better drilling efficiency. It appears that silicate based and TAME-Polyglycol based muds are the best choice to inhibit shale swelling and dispersion issues. A series of tests which must be conducted to evaluate the designed water based mud used for drilling through active shale formations was also presented at the end for those who want to ensure that their mud is properly assessed before being used in the field.

\section{References}

Aftab, A., Ismail, A.R., Ibupoto, Z.H. 2016. Enhancing the rheological properties and shale inhibition behavior of water-based mud using nanosilica, multi-walled carbon nanotube, and graphene nanoplatelet, Egypt J of Petrol, In Press 
Akhtarmanesh, S. Ameri Shahrabi M.J., Atashnezhad, A. 2013. Improvement of wellbore stability in shale using nanoparticles, J Petrol Sci Eng, 112, 290-295

Alford, S.E., 1991. North Sea field application of an environmentally responsible water-base shale stabilizing system. In: Proceedings Volume. SPE/IADC Drilling Conference, Amsterdam, the Netherland, 11-14 March 1991, pp. 341-355.

Alford, S. E., Asko, A., Campbell, M., Aston, M.S., Kvalvaag, E. K. 2005. Silicate based fluid, mud recovery system combine to stabilize surface formations of Azeri Wells, SPE/IADC conference drilling conference, Amsterdam, the Netherland, SPE/IADC 92769

Alias, N. H., Mohd Tahir, N. F., Mohd, T. A. T., Ghazali, N. A., Yahya, E., Shahruddin, M. Z., Azizi, A. 2014. Rheological Study of Nanosilica Based Drilling Fluid. Appl Mech Mat, 575, 128-133

Alonso-Debolt, M., Jarrett, M., 1995. Synergistic effects of sulfosuccinate/polymer system for clay stabilization. In: Proceedings Volume. Vol. PD-65. Asme Energy-Sources Technological Conference Drilling Technological Symposium, Houston, 29 January-1 February 1995, pp. 311-315.

Amanullah, M., Al-Tahini, A.M., 2009. Nano-technology its significance in smart fluid development for oil and gas field application. Paper Presented at SPE Saudi Arabia Section Technical Symposium, Al-Khobar, Saudi Arabia, 9-11 May, pp. 1-12.

Anderson, R. L., Ratcliffe, I., Greenwell, H. C., Williams, P. A., Cliffe, S., \& Coveney, P. V. 2010. Clay swelling - A challenge in the oilfield. Earth-Sci Rev, 98 (3-4), 201-216. doi:10.1016/j.earscirev.2009.11.003

Beihoffer, T.W., Dorrough, D.S., Schmidt, D.D., 1988. The separation of electrolyte from rheological effects in studies of inhibition of shales with native moisture contents. SPE Paper 18032. IADC/SPE Drilling Conference, Houston, TX. 2-5 October

Brady, M.E., Craster, B., Getliff, J.M., Reid, P.I., 1998. Highly inhibitive, low-salinity glycol waterbase drilling fluid for shale drilling in environmentally sensitive locations. SPE Paper 46618, SPE International Conference. Venezuela, 7-10 June.

Caenn R., Darley H. C. H., Gray, G. R. 2011. Composition and Properties of Drilling and Completion Fluids, 6th edition, Elsevier, UK

Chamberlain, D., J. Masikewich, and C. Thaemlitz. 2002. Aqueous drilling fluid and shale inhibitor. Google Patents.

Chenevert, M.E., 1970. Shale control with balanced activity oil continuous muds. J. Pet. Tech. October, 1309-1316.

Chesser, B.G., 1987. Design considerations for an inhibitive, stable water-based mud system. SPE Paper 14757, IADC/SPE Drilling Conference. Dallas, 10-12 February

Coveney, P.V., Watkinson, M., Whiting, A., Boek, E.S., 1999a. Stabilising clayey formations. GB Patent 2332 221, assigned to Sofitech NV, 16 June 1999

Devereux, S. 1998, Practical Well Planning \& Drilling Manual, First Edition, 510 p 
Downs, J. D., van Oort, E., Redman, D. I., Ripley, D., Rothmann, B. 1993. TAME: a new concept in water-based drilling fluids for shales, offshore European Conference held in Aberdeen, SPE 26699

Dye, W., d'Augereau, K., Hansen, N., Otto, M., Shoults, L., Leaper, R., Clapper, D., Xiang, T. 2006. New water-based mud balances high-performance drilling and environmental compliance. SPE/IADC Paper 92367, SPE/IADC Drilling Conference. Amsterdam, 23-25 February.

Elochukwu, H., Gholami, G., Dol, S. S. 2017. An approch to improve the cuttings carrying capcity og nanosilica based mud, J Petrol Sci Eng, 152, 309-316

Fang. H.Y. 1991. Foundation Engineering Handbook, 2nd Edition, Spring Science and Business Media, LLC, New York

Fink, J. 2011. Petroleum Engineer's Guide to Oil Field Chemicals and Fluids, 1st edition, Elsevier, USA, 808pages

Fritz, B., Jarrett, M. 2012. Potassium silicate treated water based fluid: An effective barrier to instability in the Fayetteville shale. IADC/SPE Drilling conference and exhibition, California, USA. IADC/SPE 151491

Graue, K., 2000, Mud volcanoes in deepwater Nigeria: Marine and Petroleum Geology, 17, 959974

Ghanbari, S., Naderifar, A., 2016. Enhancing the physical plugging behavior of colloidal silica nanoparticles using binomial size distribution. J. Nat. Gas. Sci. Eng. 30, 213-220.

Guerrero, X., Guerrero, M., Warren, B., 2006. Use of amine/PHPA system to drill high reactive shales in the Orito field in Colombia. SPE Paper 104010, First International Oil Conference and Exhibition. Cancun, Mexico, 31 August-2 September

Guo, J.K., Yan, J.N., Fan, W.W., Zhang, H.J., 2006. Applications of strongly inhibitive silicate-based drilling fluids in troublesome shale formations in Sudan. J Pet Sci Engin, 50, 195-203.

Hale, A.H., van Oort, E., 1997. Efficiency of ethoxylated/propoxylated polyols with other additives to remove water from shale. US Patent 5602082

Himes, R.E., 1992. Method for clay stabilization with quaternary amines. US Patent 5097904 , assigned to Halliburton Co.

Horton, D., Jones, A., 1998. Clay stabilizing agent and a method of use in subterranean formations to inhibit clay swelling. US 5771971.

Jianga, W., Z. Y., Goua, S., Liub, X., Liangb, L., Wangc W., Songa. Z. 2015. Modular $\beta$-cyclodextrin and polyoxyethylene ether modified water-soluble, Poly Adv Tech, 27 (2), 213-220

Khodja, M., Canselier, J.P., Bergaya, F., Fourar, K., Khodja, M., Cohaut, N., Benmounah, A., 2010. Shale problems and water-based drilling fluid optimization in the Hassi Messaoud Algerian oil field. Appl. Clay. Sci. 49, 383-393. 
Lal, M., 1999. Shale stability: drilling fluid interaction and shale strength. SPE Paper 54356, SPE Latin American and Caribbean Petroleum Engineering Conference. Venezuela, 21-23 April.

Li., T., Wu, C. 2015. Research on the Abnormal Isothermal Adsorption of Shale, Energy Fuels, 29, 634-640

Liu, J.Y., Qiu, Z.-S., Huang, W., 2015. Novel latex particles and aluminum complexes as potential shale stabilizers water-based drilling fluids. J. Pet. Sci. Eng. 135, 433-441.

Mballa Mballa, M. A., Heuts, J. P.A., van Herk, A. M. 2013. Encapsulation of non-chemically modified montmorillonite clay platelets via emulsion polymerization, Colloid Polym Sci, 291, 501-513

McDonald, M., Barr, K., Dubberley, S. R., Wadsworth, G. 2007. Use of silicate based drilling fluids to mitigate metal corrosion, SPE international symposium on oilfield chemistry, Houston, Texas, USA, SPE 100599

Metin, C., Bonnecaze, R., Nguyen, Q. 2013. The Viscosity of Silica Nanoparticle Dispersions in Permeable Media, SPE Res Eval Eng, 16 (3), SPE-157056-PA

Mitchell, R. F., Miska, S. Z. 2011. Fundamentals of drilling engineering, SPE text book series, Vol 12, Society of Petroleum engineers, USA

Moslemizadeh, A., Aghdam, S. K.-Y, Shahbazi, K., Aghdam, H. K.-Y, Alboghobeish, F., 2016. Assessment of swelling inhibitive effect of CTAB adsorption on montmorillonite in aqueous phase. Appl. Clay. Sci. 127-128, 111-122.

Moslemizadeh, A., Shadizadeh, S.R., Moomenie, M., 2015. Experimental investigation of the effect of henna extract on the swelling of sodium bentonite in aqueous solution. Appl. Clay Sci. 105, 78-88.

Osuji, C.E., Chenevert, M.E., Sharma, M.M., 2008. Effect of porosity and permeability on the membrane efficiency of shales. SPE Annual Technical Conference, Colorado, USA, 21- 24 September. SPE 116306

Patel, A. D. 2009. Design and Development of Quaternary Amine Compounds: Shale Inhibition With Improved Environmental Profile. SPE International Symposium on Oilfield Chemistry, 20-22 April, The Woodlands, SPE-121737-MS

Patel, A.D., McLaurine, H.C., 1993. Drilling fluid additive and method for inhibiting hydration. CA Patent 2088 344, assigned to M I Drilling Fluids Co

Patel, A., Stamatakis, E., Friedheim, J.E., Davis, E., 2001. Highly inhibitive water-based fluid system provides superior chemical stabilization of reactive shale formations. Paper presented at the AADE National Technical Conference and Exhibition, Texas, USA.

Patel, A.D., Stamatakis, E., Young, S., Friedeim, J., 2007. Advances in inhibitive water-based drilling fluids-can they replace oil-based muds? SPE Paper 106476, SPE International Symposium on Oilfield Chemistry. Houston, Texas, 28 February-2 March 
Peng, C., Yan J., Feng, W. 2010. An Offshore Benign WBM System Can Prevent Hard, Brittle Shale Instability, Pet Sci Tech, 28:12, 1230-1241

Pervukhina, M., Gurevich, B., Golodoniuc, P., Dewhurst, D. N. 2011. Parameterization of elastic stress sensitivity in shales, Geophysics, 76, (3), 147-155

Pezhman, B., Sadegh, K., Amirhossein, A., Khalil, S., Ali, M., 2016. Inhibition performance and mechanism of horsetail extract as shale stabilizer. Petrol. Explor. Develop. 43(3), 522-527.

Qu, Yuanzhi, Xiaoqing Lai, LaifangZou, and Yi'nao Su. 2009. Polyoxyalkyleneamine as shale inhibitor in water-based drilling fluids. Appl Clay Sci, 44 (3-4):265-268. doi: http://dx.doi.org/10.1016/j.clay.2009.03.003.

Retz, R. H., J. Friedheim, L. J. Lee, and O. O. Welch. 2006. An Environmentally Acceptable and Field-Practical, Cationic Polymer Mud System. 1991/1/1/.

Sashikumar, M., Stamatakis, E., Young, S., De Stefano, G., 2011. The prevention and cure of bit balling in water-based drilling fluids. Paper presented at the AADE fluids conference and exhibition, Houston, USA.

Shadizadeh, S. R., Moslemizadeh, A., Shirmardi Dezaki. A 2015. A novel nonionic surfactant for inhibiting shale hydration. Appl Caly Sci, 118, 74-86

Smith, C.K., Balson, T.G., 2000. Shale-stabilizing additives. GB Patent 2340 521, assigned to Sofitech NV and Dow Chemical Co

Soric, T., Naftaplin, I., Marinescu, P., Huelke, R. 2004. Silicate based drilling fluid deliver optimum shale inhibition and wellbore stability, IADC/SPE drilling conference, Dalas, Texas, USA, IADC/SPE 87133

Steiger, R.P., 1981. Fundamentals and use of potassium/polymer drilling fluids to minimize drilling and completion problems associated with hydratable clays. SPE Paper 10100, SPE 56th Annual Technical Conference and Exhibition. San Antonio, 5-7 October

Steiger, R., Leung, P.K., 1992. Quantitative determination of the mechanical properties of shales. Paper SPE 18024, SPE Drilling Eng, 7 (3), pp. 181-185.

Stephens, M., Gomez-Nava, S., Churan, M., 2009. Laboratory methods to assess shale reactivity with drilling fluids. Paper presented at the AADE National Technical Conference and Exhibition, Louisiana, USA.

Stowe, C., Bland, R.G., Clapper, D., Xiang, T., Benaissa, S., 2002.Water-based drilling fluids using latex additives. GB Patent 2363 622, assigned to Baker Hughes Inc.

Stowe, C., Halliday, W., Xiang, T., Morton, K., Hartman, S., 2001. Laboratory pore pressure transmission testing of shale. Paper presented at the AADE National Drilling Conference, Texas, USA.

Suter, J. L., P. V. Coveney, R. L. Anderson, H. C. Greenwell, and S. Cliffe. 2011. Rule based design of clay-swelling inhibitors. Energy Env Sci, 4 (11):4572-4586. doi: 10.1039/C1EE01280K.

Van Oort, E., 2003. On the physical and chemical stability of shales. J. Petrol. Sci. Eng 38, 213235. 
Westerkamp, A., Wegner, C., Mueller, H.P., 1991. Borehole treatment fluids with clay swellinginhibiting properties (ii) (bohrloch- behandlungsfluessigkeiten mit tonquellungsinhibierenden eigenschaften (ii)). EP Patent 451 586, assigned to Bayer AG

Xuan, Y., Jiang, G., Li, Y, Wang, J., Geng, H., 2013. Inhibiting effect of dopamine adsorption and polymerization of hydrated swelling of montmorillonite. Colloids and Surfaces A: Physicochem. Eng. Aspects 422, 50-60.

Xuan, Y., G. J., Li, Y., Yanga, L., Zhanga. X. 2015. Biodegradable oligo (poly-L-lysine) as a highperformance, Royal society of chemistry. doi:10.1039/C5RA16003K

Zengeni, E., Hartmann, P. C., Pasch, H. 2012, Encapsulation of Clay by Ad-Miniemulsion Polymerization: The Influence of Clay Size and Modifier Reactivity on Latex Morphology and Physical Properties, Appl. Mater. Interfaces 2012, 4, 6957-6968

Zeynali, M.E., 2012. Mechanical and physico-chemical aspects of wellbore stability during drilling operations. J. Pet. Sci. Eng. 82, 120-124.

Zhou, D., Zhang, Z., Tang, J., Wang, F., Liao, L., 2015. Applied properties of oil-based drilling fluids with montmorillonites modified by cationic and anionic surfactants Appl. Clay. Sci. 122, 1-8.

Zhong, H. Y., Z. S. Qiu, W. A. Huang, J. Qiao, H. B. Li, and J. Cao. 2013. The Development and Application of a Novel Polyamine Water-based Drilling Fluid. Petrol Sci Technol, 32 (4): 497-504. doi: 10.1080/10916466.2011.592897.

Zhong, H., Qiu, Z., Huang, W., Cao. J., 2012. Poly (oxypropylene)-amidoamine modified bentonite as potential shale inhibitor in water-based drilling fluids. Appl Clay Sci, 67-68 (0):36-43.

Zhong, H., Qiu, Z., Huang, W., Xie, B., Wang. W. 2013. Bis (hexamethylene) triamine as Potential Shale Inhibitor in Water-Based Drilling Fluid. Open Pet Eng J. 6:49-56.

Zhong, H., Qiu, Z., Sun, D., Zhang, D., Huang, W. 2015. Inhibitive properties comparison of different polyetheramines in water-based drilling fluid. J Natural Gas Sci and Eng, 26, 99107. doi:10.1016/j.jngse.2015.05.029 